\title{
EFEITO DA SUPLEMENTAÇÃO NO DESEMPENHO DE BOVINOS DE CORTE EM PASTAGEM DE Brachiaria brizantha cv. MARANDU ${ }^{1}$
}

\author{
Supplementation effect on the performance of beef cattle steers maintained \\ in Brachiaria brizantha cv. Marandu pasture
}

\author{
Leonardo de Oliveira Fernandes ${ }^{2}$, Ricardo Andrade Reis ${ }^{3}$, José Mauro Valente Paes ${ }^{2}$
}

\begin{abstract}
RESUMO
Conduziu-se este trabalho, com o objetivo de avaliar o efeito da suplementação protéico-energética, durante o período das águas sobre o ganho de peso de bovinos mestiços (1/2 Nelore + 1/2 Blonde D'Aquitaine) mantidos em pastagem Brachiaria brizantha (A. Rich.) Stapf cv. Marandu. Avaliou-se a produção e a composição química da forragem. Foram utilizados 18 novilhos com peso médio de $181 \mathrm{~kg}$, distribuídos em um delineamento em blocos ao acaso, em parcela subdividida, alocando o tratamento na parcela e o período na subparcela, com dois tratamentos e nove repetições; os tratamentos foram: sem suplementação (SS) e suplementados com concentrado em $0,6 \%$ do peso (SA). Foi verificado, durante o período das águas, aumento $(\mathrm{P}<0,05)$ no ganho de peso dos novilhos $(1,06 \mathrm{~kg} / \mathrm{dia})$ comparado aos novilhos que não receberam suplementação $(0,77 \mathrm{~kg} / \mathrm{dia})$.
\end{abstract}

Termos para indexação: Forragem, ganho de peso, pastejo rotacionado, suplemento, Brachiaria brizantha.

\section{ABSTRACT}

This research was conducted to evaluate the energy and protein supplementation effects on the weight gain of crossbred steers ( $1 / 2$ Nellore $+1 / 2$ Blonde D'Aquitaine) maintained in Brachiaria brizantha (A. Rich.) Stapf cv. Marandu pasture, during the rainy season. Forage production and chemical composition were determined. Eighteen (18) steers with average body weight (BW) of $181 \mathrm{~kg}$ were evaluated and distributed in a randomized block design, in a split-plot scheme, allocating the plot and the sub-plot periods, with two treatments and six replications. Treatments were: no supplement (SS), supplementation with $0.6 \%$ of BW (SA). During the rainy season, the supplementation increased the weight gain of the steers $1.06 \mathrm{~kg} /$ day (SA), compared to $0.77 \mathrm{~kg} / \mathrm{day}$ (SS).

Index terms: Forage, weight gain, rotational grazing, supplement, Brachiaria brizantha.

(Recebido em 8 de outubro de 2008 e aprovado em 30 de abril de 2009)

\section{INTRODUÇÃO}

$\mathrm{Na}$ maioria dos sistemas de produção de carne bovina do Brasil são observadas baixas produções. $\mathrm{O}$ principal fator limitante é a variação crítica na produção e qualidade da forragem ao longo do ano. $\mathrm{Na}$ época das águas, verifica-se alta produção de forragem obtendo-se $85 \%$ da produção anual, com qualidade nutricional adequada, enquanto que, durante a época da seca, observam-se limitações quanti-qualitativas.

Essa variação na produção e qualidade do pasto durante o ano limita a utilização do potencial genético dos bovinos mantidos em pastagem, verificando durante a época das águas, ganho de peso entre 0,5 e $0,8 \mathrm{~kg} / \mathrm{dia}$ (Poppi \& Mclennan, 1995) e ganhos baixos ou perda de peso durante a seca. O resultado desse baixo desempenho é o abate tardio de bovinos, próximo aos 48 meses (Zimmer \& Euclides Filho, 1997) e qualidade inferior da carne, dificultando a exportação, tornando o setor ineficiente do ponto de vista técnico e econômico.

Para que ocorra diminuição na idade de abate de bovinos mantidos em pastagem (abaixo de 22 meses) é necessário que o ganho em peso esteja próximo do potencial genético dos animais atingindo ganho em peso acima de $0,8 \mathrm{~kg} /$ dia durante á época das águas e promover, durante a seca, ganhos de $0,9 \mathrm{~kg} /$ dia em sistemas de terminação que eliminem as deficiências nutricionais do pasto. Assim se poderia melhorar a qualidade da carne produzida e aumentar o giro sobre o capital investido na atividade, gerando maior lucratividade.

Em relação a forragens de clima tropical, existem poucas informações sobre o quanto o teor de proteína é limitante ao desenvolvimento de animais no período das águas. Porém, ao lançar mão de suplementos com altas quantidades de proteína é possível obter ganho de peso adicional de 200 a 300g/dia (Poppi \& Mclennan, 1995).

${ }^{1}$ Parte da tese de Doutorado do primeiro autor apresentada à FCAV - UNESP - Trabalho realizado através da parceria - EPAMIG/FAZU/FCAVUNESP

${ }^{2}$ Pesquisadores da EPAMIG - Professores da FAZU - Bolsistas da FAPEMIG - Rua Afonso Rato - 1301 - Cx. P. 351 - $38001-970$ - Uberaba, MG leonardo@epamiguberaba.com.br ; jpaes@epamiguberaba.com.br

${ }^{3} \mathrm{UNESP} / J a b o t i c a b a l$ - Jaboticabal, SP 
Por outro lado, durante o período das águas, o fornecimento de energia prontamente digestível, diminui a perda de nitrogênio da forragem, obtendo-se um melhor balanço entre a energia disponível e a amônia no rúmen, aumentando a síntese de proteína microbiana, permitindo um melhor desempenho animal (Moore et al., 1999).

Neste trabalho, objetivou-se avaliar o efeito da suplementação de bovinos de corte durante o período das águas, manejados em pastagem de Brachiaria brizantha (A. Rich.) Stapf cv. Marandu (capim Marandu), além de determinar a produção e a composição química desta forrageira durante os períodos das águas e seca.

\section{MATERIAL E MÉTODOS}

O trabalho foi desenvolvido nas áreas da FAZU Faculdades Associadas de Uberaba e da Unidade de Pesquisa da EPAMIG - Empresa de Pesquisa Agropecuária de Minas Gerais - EPAMIG, no município de Uberaba/MG. A determinação da produção e composição química da forrageira foi realizada entre 27/11/2001 e 26/11/2002 sendo que o desempenho de bovinos suplementados durante o período das águas foi avaliado entre 19/12/2001 e 20/04/2002.

A cidade de Uberaba está localizada a $19^{\circ} 45^{\prime} 56^{\prime \prime}$ de latitude sul e $47^{\circ} 57^{\prime}$ de longitude oeste, numa altitude de $774 \mathrm{~m}$, com clima tropical semiúmido, sendo a temperatura média de $21,4^{\circ} \mathrm{C}$. A precipitação anual média é de 1684,6 mm e a umidade média relativa do ar é de 71,4\%, dados obtidos (Figura 1) na Estação Climatológica Principal de Uberaba -Epamig/INMET (2003).

Foram utilizados 18 bovinos mestiços $(1 / 2$ Nelore + $1 / 2$ Blonde D‘Aquitaine) com seis meses de idade, machos, inteiros, com peso inicial de $181 \mathrm{~kg}$. No início do período experimental foram procedidas as desverminações, vacinações e a marcação individual dos animais. Essa etapa foi iniciada em 19/12/2001 com término em 20/04/2002, totalizando 122 dias, sendo 14 dias para período de adaptação e 108 dias para avaliação.

Durante todo o período experimental foram realizados os controles rotineiros de ectoparasitos e as desverminações necessárias, procedendo-se às pesagens após jejum completo de 14 horas a cada 36 dias. Foi fornecido sal mineralizado, durante o período experimental, com os seguintes níveis de garantia por $\mathrm{kg}$ do produto: $120 \mathrm{~g} \mathrm{Ca}, 82 \mathrm{~g}$ de $\mathrm{P}, 15 \mathrm{~g}$ de $\mathrm{Mg}, 121 \mathrm{~g} \mathrm{Na}, 2,2 \mathrm{~g}$ de S, 130mg de Co, $1160 \mathrm{mg}$ de $\mathrm{Cu}, 1120 \mathrm{mg}$ de F, $120 \mathrm{mg}$ de I, 1325mg de $\mathrm{Mn}, 33 \mathrm{mg}$ de Se e $4670 \mathrm{mg}$ de $\mathrm{Zn}$.

A área experimental foi constituída por 3,3 ha de capim Marandu, divididos em três conjuntos, sendo que cada conjunto foi dividido em nove piquetes de 0,122 ha manejados pelo método de lotação rotacionada.
O solo da área experimental foi classificado como Latossolo Vermelho Distrófico, textura Franco Arenosa (Embrapa, 1999), com relevo suave. Conforme os dados da análise do solo da área de pastejo (Tabela 1) foram feitas as correções e adubações de manutenção. Foram aplicados $500 \mathrm{~kg} / \mathrm{ha}$ de calcário dolomítico no final do período da seca de 2001. As adubações foram realizadas, ao longo do período das águas, parceladas em cinco aplicações ( $\mathrm{N}$ e $\mathrm{K}_{2} \mathrm{O}$ ), imediatamente após a saída dos animais do piquete. A adubação com fósforo foi realizada em novembro de 2001. Para a determinação da adubação, foi observado o nível de extração de nutrientes pela matéria seca (MS) produzida (Werner et al., 1997). Foram utilizados $300 \mathrm{~kg}$ de N/ha, $90 \mathrm{~kg}$ de $\mathrm{P}_{2} \mathrm{O}_{5} /$ ha e $150 \mathrm{~kg}$ de $\mathrm{K}_{2} \mathrm{O} / \mathrm{ha}$.

Durante o período das águas nos três conjuntos manejados pelo método de lotação rotacionada, cada um dividido em nove piquetes, foi adotado manejo de pastagem que proporcionou quatro dias de ocupação e 32 dias de descanso, propiciando oferta de forragem de $4,0 \%$ de matéria seca em relação ao peso corporal médio, considerando a forragem acima de $0,25 \mathrm{~m}$ de altura do solo.

Foram avaliados os seguintes tratamentos experimentais:

SS - Bovinos mantidos em pastejo rotacionado de capim Marandu, sem suplementação de concentrado;

SA - Bovinos mantidos em pastejo rotacionado de capim Marandu, com suplementação de concentrado na quantidade de $0,6 \%$ do peso.

Durante o período da seca foram avaliados os parâmetros de produção e composição química da forragem, adotando manejo que proporcionou seis dias de ocupação e 48 dias de descanso, propiciando oferta de forragem de $6,0 \%$ do peso corporal médio, considerando a forragem acima de $0,25 \mathrm{~m}$ de altura do solo. A maior oferta de forragem utilizada para este período foi utilizada para estimular a seletividade e desempenho animal, além de proporcionar melhores condições de manejo (recuperação da pastagem após o pastejo). Para realizar o manejo da pastagem foram utizados bovinos que receberam suplemento durante todo o período da seca.

A suplementação foi formulada por meio do sistema proposto pelo Agricultural and Food Research CouncilAFRC (1995) para ganho de peso de 1,0 kg/animal/dia (Tabela 2). O suplemento foi fornecido individualmente em baias, para controlar a quantidade de concentrado ingerido, uma vez ao dia às $7 \mathrm{~h}$. O suplemento utilizado possuía a seguinte composição: 70,9 \% de milho grão; 8,5 \% de farelo de soja; $13,6 \%$ de farinha de glúten de milho com $60 \%$ de PB (glutenose); 4,1 \% de uréia; 0,4 \% de sulfato de amônio; $1,5 \%$ de fosfato bicálcico e $1,0 \%$ de melaço em pó. 


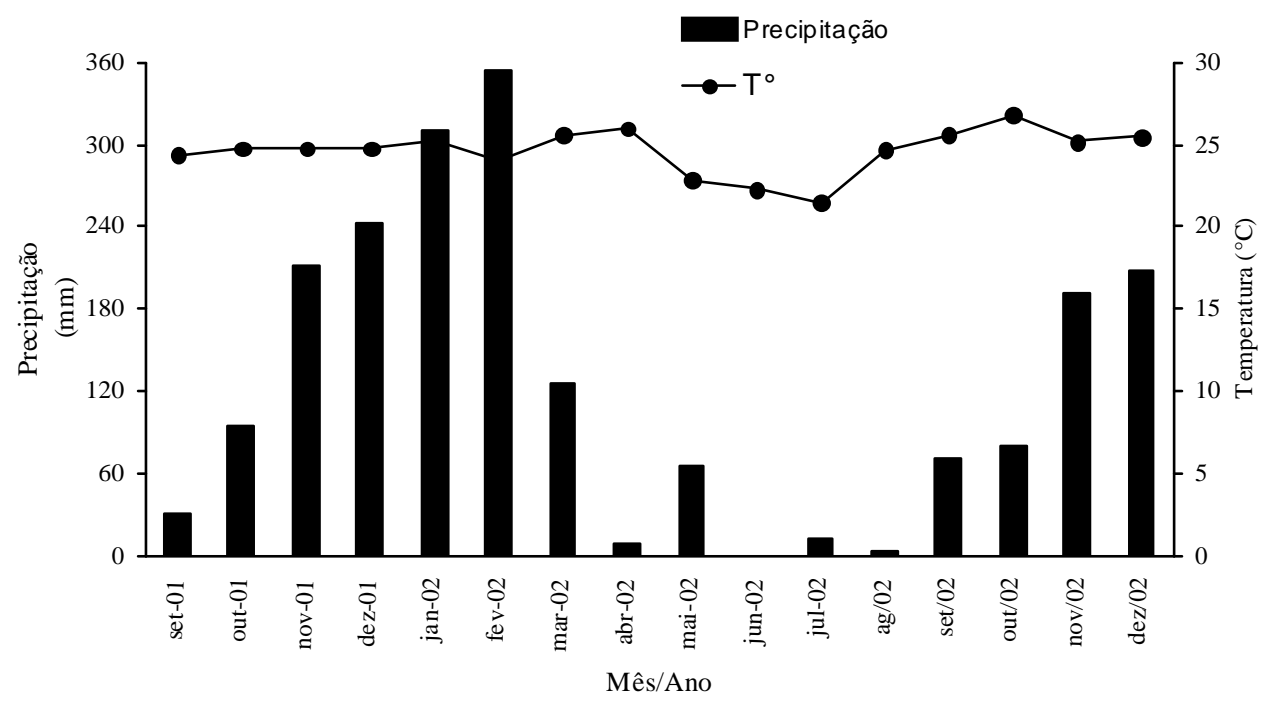

Figura 1 - Condições climáticas obtidas na Estação Climatológica Principal de Uberaba - Epamig/INMET (2003).

Tabela 1 - Resultados da análise do solo na camada de 0 a $20 \mathrm{~cm}$ colhida em maio de 2001.

\begin{tabular}{|c|c|c|c|c|c|c|c|c|c|c|c|c|}
\hline $\mathrm{pH}$ & $\mathrm{P}^{1}$ & $\mathrm{~K}$ & $\mathrm{Ca}$ & $\mathrm{Mg}$ & $\mathrm{H}+\mathrm{Al}$ & SB & CTC & $\mathrm{V}$ & Areia & Limo & Argila & MO \\
\hline $\mathrm{H}_{2} \mathrm{O}$ & \multicolumn{2}{|c|}{$\mathrm{mg} / \mathrm{dm}^{3}$} & \multicolumn{5}{|c|}{ Cmolc/dm ${ }^{3}$} & \multicolumn{4}{|c|}{$\%$} & $\mathrm{Dag} / \mathrm{dm}^{3}$ \\
\hline 6,2 & 3,1 & 102 & 2,0 & 0,5 & 2,1 & 2,8 & 4,9 & 57 & 65 & 7 & 28 & 2,4 \\
\hline
\end{tabular}

${ }^{1}$ Método Mehlich

Fonte: Dados obtidos através de análise realizada no laboratório de análises de solos da FAZU - Uberaba/MG

O delineamento utilizado para a avaliação de desempenho animal (período das águas) foi em blocos ao acaso (bloco $=$ conjunto de piquetes manejados em lotação rotacionada) em parcelas subdivididas. Nas parcelas foram colocados os tratamentos e na subparcela os períodos de avaliação (período = ciclo de pastejo; utilizaram-se três períodos). Foram utilizados dois tratamentos e nove repetições. As médias foram comparadas pelo teste de Tukey a 5\%. Dessa maneira, pode-se manter em cada bloco três animais de cada tratamento, eliminando o efeito de possíveis diferenças na qualidade da forragem disponível.

As variáveis estudadas foram avaliadas utilizandose o Sistema de Análises Estatísticas e Genéticas - SAEG (Universidade Federal de Viçosa-UFV, 1997).

Para manter a oferta de forragem em $4,0 \%$ de matéria seca em relação ao peso do animal, foram feitas estimativas da oferta de forragem a cada entrada dos animais no piquete, e, com base nessa informação, e no peso médio dos animais, foi realizado o ajuste na taxa de lotação.

A oferta de forragem foi avaliada em $0,5 \%$ da área total do piquete, sendo cortadas e pesadas, procedendo à colheita de amostra para análise laboratorial ('t Mannetje, 1978). A avaliação da oferta de forragem foi feita por meio da realização de seis cortes aleatórios no piquete com o quadrado de 1,0 x 1,0 m no momento da entrada dos animais, respeitando-se o resíduo de $0,25 \mathrm{~m}$. Para ajustar a oferta de forragem, os bovinos testadores foram acompanhados por outros animais, quando necessário, no sistema "put and take”, conforme proposto por Mott \& Lucas (1952).

As amostras de forragem para as análises laboratoriais foram colhidas naquela cortada para a avaliação da oferta, em cada mudança dos bovinos de piquetes, perfazendo uma amostra composta (MS disponível acima de $0,25 \mathrm{~m}$ ) a cada ciclo de pastejo (36 dias).

Nas amostras de forragem, nos alimentos utilizados no balanceamento do suplemento e nos suplementos foram determinados os teores de matéria seca, nitrogênio total, fibra em detergente neutro (FDN), fibra em detergente ácido (FDA), hemicelulose e de lignina, segundo Silva (2002). A composição química da forragem e do suplemento encontrase na Tabela 2. 
Tabela 2 - Composição químico - bromatológica do capim-Marandu e dos suplementos utilizados durante o período das águas, em porcentagem da MS.

\begin{tabular}{lcc}
\hline \multicolumn{1}{c}{ Itens $^{1}$} & Forragem & Suplemento \\
\hline Matéria seca & 19,7 & 92,1 \\
Proteína bruta & 13,3 & 30,5 \\
Fibra em detergente neutro & 70,7 & 11,2 \\
Fibra em detergente ácido & 38,5 & 4,8 \\
Celulose & 33,4 & - \\
Hemicelulose & 32,2 & 6,4 \\
Lignina & 5,1 & - \\
Extrato etéreo & - & 2,9 \\
Matéria Mineral & - & 2,2 \\
NDT $^{2}$ & $61,0 *$ & $82,7^{* *}$ \\
\hline
\end{tabular}

Dados obtidos através das análises laboratoriais procedidas no Laboratório de forragicultura da UNESP/Jaboticabal.

${ }^{2}$ Nutrientes digestíveis totais - valores estimados * Boin (1994); ** Kearl (1982).

$\mathrm{Na}$ avaliação dos dados da forragem, foi utilizado um delineamento em blocos ao acaso (bloco $=$ piquetes manejados em lotação rotacionada), com 8 tratamentos (períodos) e três repetições, procedendo a um estudo de regressão para avaliar a produção e a composição química da forragem, durante o período das águas e seca.

\section{RESULTADOS E DISCUSSÕES}

Foi observada produção de matéria seca de 29.138 $\mathrm{kg} / \mathrm{ha} / \mathrm{ano}$, sendo $20.423 \mathrm{~kg} / \mathrm{ha}$ durante o período das águas e $8.715 \mathrm{~kg} / \mathrm{ha}$ durante o período seco. A produção de massa seca verificada é superior a reportada por Fernandes et al. (2003a,b) que verificaram produção de matéria seca de $21.130 \mathrm{~kg} / \mathrm{ha}$.

Pode-se notar que houve efeito de período (Figura 2) sobre a produção de matéria seca de forragem (PMS) (F < $0,01)$ e sobre a taxa de lotação (TLOT) $(\mathrm{F}<0,01)$. Houve concentração da produção de matéria seca durante o período das águas $(70,1 \%)$ em relação ao período da seca $(29,9 \%)$. Quanto à taxa de lotação, pode-se dizer que a expressiva redução verificada durante a seca, além de poder ser atribuída à diminuição na produção neste período, devese também a maior oferta de forragem estabelecida durante o referido período.

Considerando produção possível de $8.000 \mathrm{~kg}$ de matéria seca de forragem/ha (Fernandes et al., 2003a,b), com a fertilidade natural dos solos de Cerrado e a produção verificada nesse experimento, pode-se estimar que a resposta à adubação nitrogenada foi de $70 \mathrm{~kg}$ de massa seca adicional por $\mathrm{kg}$ de nitrogênio aplicado durante o período de um ano. Essa resposta à adubação nitrogenada está de acordo com os resultados relatados por Corsi \& Nússio (1993), que observaram respostas variando entre 40 a $70 \mathrm{~kg}$ de matéria seca por $\mathrm{kg}$ de nitrogênio utilizado.

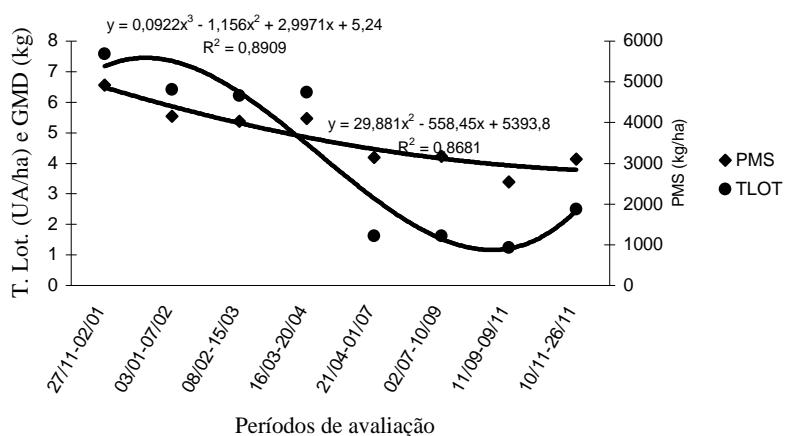

Figura 2 - Produção de matéria seca (PMS) e taxa de lotação (TLOT) observados.

As produções de matéria seca, com as distribuições observadas, demonstram que sistemas manejados em lotação rotacionada com capim marandu, adubados e bem manejados são capazes de produzir alta quantidade de massa seca com distribuição dessa produção mais homogênea durante todo o ano, diminuindo o efeito da estacionalidade da produção de forragem sobre o ganho em peso de bovinos ao longo do ano.

Nunes et al. (1984) relataram produção de 20 toneladas de matéria seca/ha/ano de capim marandu em experimento para avaliar o potencial produtivo de matéria seca em resposta à adubação. Pedreira \& Matos (1981) observaram diferença entre as produções de forragem do capim Brachiaria decumbens Stapf cv. Ipean com valores de $83 \%$ e $17 \%$, e do capim B. decumbens cv. Basilisk, produzindo $88 \%$ e $12 \%$, dados referentes às produções do período das águas e da seca. Os mesmos autores relataram produção de 14,50 toneladas de matéria seca/ha/ano para o capim $B$. decumbens cv. Basilisk.

Por meio da análise dos dados apresentados (Figuras 3 e 4) pode-se constatar que independentemente do período, a composição química da forragem disponível permaneceu constante. Entre os períodos das águas e seca os conteúdos de FDN, FDA, hemicelulose e celulose apresentaram os mesmos valores, aumentando o conteúdo de lignina $(\mathrm{F}<0,01)$ durante o período da seca. O conteúdo de PB 
apresentou variação $(\mathrm{F}<0,01)$, diminuindo durante o mesmo período.

Associando esta observação com o ganho em peso, nota-se que como a composição química permaneceu constante durante o período das águas, não houve efeito de período no ganho de peso dos animais $(\mathrm{F}<0,01)$, justificando também porque a diferença entre os tratamentos (SA e SS) permaneceu constante durante os períodos avaliados.

Pode-se inferir então que a suplementação promoveu efeito positivo sobre o consumo de nutrientes durante o período das águas, aumentando a eficiência de utilização da forragem, com consequente melhoria no ganho de peso dos bovinos submetidos à estratégia de suplementação. Essa verificação pode ser justificada também pela alta qualidade da forragem disponível durante o período das águas.

Os resultados do ganho médio diário (GMD), peso inicial (PI), peso final (PF) e ganho de peso no período das águas são apresentados na Tabela 3. Com relação ao ganho de peso dos bovinos submetidos aos diferentes tratamentos, constata-se que no final do período das águas os bovinos suplementados apresentavam $30 \mathrm{~kg}$ de peso a mais em relação aos bovinos que não receberam suplementação. Esta diferença poderia possibilitar diminuição no período de terminação dos bovinos, diminuindo o custo de produção da arroba, pois durante o período da seca os custos para de alimentação são maiores do que aqueles observados no período das águas.

Analisando os dados, pode-se verificar que a suplementação promoveu aumento no ganho de peso durante o período das águas $(\mathrm{P}<0,05)$, observandose valores de 0,77 e $1,06 \mathrm{~kg} /$ bovino/dia, respectivamente nos bovinos que não receberam suplementação e os suplementados com $0,6 \%$ do peso médio corporal.

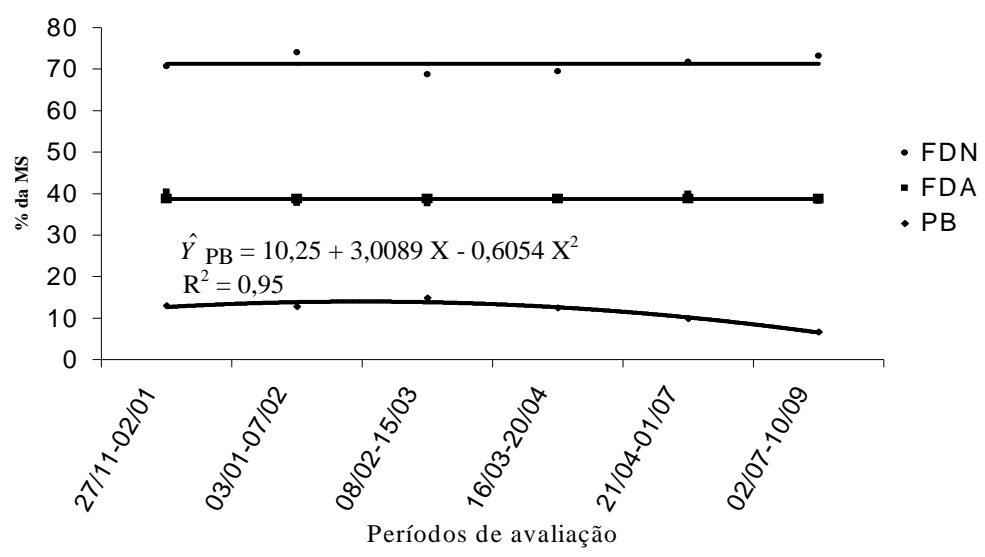

Figura 3 - Conteúdo de FDN, FDA, PB da forragem disponível durante o período experimental.

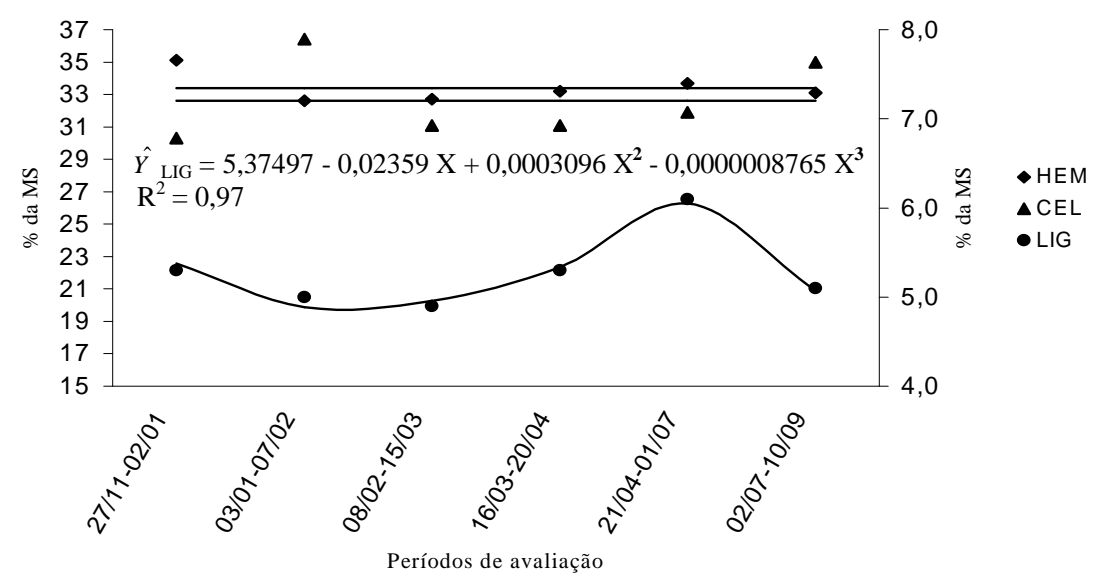

Figura 4 - Conteúdo de hemicelulose, celulose e lignina da forragem disponível ao longo do ano. 
Tabela 3 - Ganho médio diário (GMD), peso inicial (PI), final (PF), ganho de peso no período (GPP) de novilhos mestiços (Nelore x Blonde D'Aquitaine), mantidos em pastagens de capim marandu no período das águas, recebendo ou não suplemento.

\begin{tabular}{lcccc}
\hline Tratamento & GMD & PI & PF & GPP \\
\cline { 5 - 6 } & $(\mathrm{kg} / \mathrm{dia})$ & & $(\mathrm{kg})$ & \\
\hline SS & $0,77 \mathrm{~b}$ & 181 & 265 & 84 \\
SA & $1,06 \mathrm{a}$ & 181 & 295 & 114 \\
\hline CV $(\%)$ & 18,5 & -- & --- & --- \\
\hline
\end{tabular}

Médias seguidas de mesma letra na coluna, não diferem pelo teste de Tukey a 5\% de probabilidade SS - Bovinos sem suplementação; SA - Bovinos suplementados com $0,6 \%$ do peso.

O incremento no peso observado nos bovinos suplementados em relação aos sem suplementação no período de 108 dias foi de $37 \%$. Pode-se atribuir o aumento no ganho em peso verificado ao maior aporte de energia, proteína total e proteína de baixa degradabilidade, fornecido pelo concentrado. Segundo Poppi \& McLennan (1995), no período das águas a forragem disponível apresenta alta concentração de nitrogênio solúvel, ocorrendo desequilíbrio entre a disponibilidade de energia e do nitrogênio disponível. Nesse caso o fornecimento de energia prontamente fermentável pode melhorar a síntese de proteína microbiana.

O aumento verificado no ganho em peso dos bovinos suplementados com $0,6 \%$ de MS em relação ao peso corporal médio pode ser atribuído ao efeito associativo do suplemento, pois a forragem disponível apresentava alta qualidade (Tabela 2) e, nesta situação, pode-se inferir que tenha ocorrido diminuição no consumo de matéria seca da forragem em função do fornecimento de suplemento, principalmente por que este era rico em energia (Hodgson, 1990; Moore et al., 1999).

Zervoudakis et al. (2001) estudaram o desempenho de bovinos Holandês-Zebu suplementados durante o período das águas ( 1 e $2 \mathrm{~kg} /$ novilho/dia) em pastagem de Brachiaria decumbens, concluindo que sob condições de alta disponibilidade de forragem (6836 kg de MS/ha) a suplementação pode não trazer os benefícios esperados (aumento do desempenho).

É importante considerar que alta disponibilidade de forragem por longos períodos, como verificado no trabalho de Zervoudakis et al. (2001), trará problema de manejo de pastagem, pois será acumulada alta quantidade de forragem de baixa qualidade que, posteriormente, comprometerá o desempenho animal, caracterizando subpastejo.
Marcondes et al. (2001), trabalhando com suplementação da dieta de bovinos mantidos em pastagem durante a época das águas, também observaram aumento no ganho em peso dos animais suplementados (aumento de $0,27 \mathrm{~kg} /$ bovino/dia), demonstrando o benefício da suplementação durante a época das águas.

Nesse experimento para os bovinos suplementados com $0,6 \%$ de MS em relação ao peso corporal médio do animal foi utilizado $1,4 \mathrm{~kg}$ de MS de suplemento/dia, obtendo ganho em peso adicional de $0,29 \mathrm{~kg} /$ bovino/dia. Esse resultado, em termos práticos, significa que para cada $\mathrm{kg}$ de peso adicional produzido como efeito da suplementação foram utilizados $4,8 \mathrm{~kg}$ de $\mathrm{MS}$ de suplemento.

Conforme foi descrito por Euclides et al. (2001) e Reis et al. (2003), a utilização de suplementação no período das águas em pastagens de alta qualidade tem efeito substitutivo no consumo de forragem (redução). Nesse experimento, pode ter ocorrido o efeito substitutivo, apesar de ser observado aumento no desempenho dos bovinos suplementados. Essa redução no consumo de MS pode ser usada em benefício do sistema, pois significa que poderia ser reduzida a oferta de forragem para bovinos suplementados, o que tornaria possível o aumento na capacidade de suporte da pastagem.

Nesse experimento foram verificadas taxas de lotação de 5,81 e 1,49 UA/ha, respectivamente no período das águas e seca. Os valores estão compatíveis com a adubação planejada que possibilitou alta produção de MS, justificando as taxas de lotação verificadas.

Associando os resultados referentes à taxa de lotação e ganho em peso dos animais recebendo a suplementação e manejados pelo método de lotação rotacionada durante o período das águas, pôde-se estimar o ganho de peso de 1.064 e $1.888 \mathrm{~kg}$ de peso/ha durante o período das águas (27/11/2001 e 20/04/2002), respectivamente, para o tratamento que os bovinos não foram suplementados e para o tratamento que utilizou a suplementação dos bovinos com $0,6 \%$ do peso corporal médio.

Nesta estimativa, foi considerado um possível aumento na capacidade de suporte $(30 \%)$, como relatado por Euclides et al. (2001) e Prohmann et al. (2002), em função de redução no consumo de MS de forragem e de efeito substitutivo (Tabela 4).

Como se pode visualizar na Tabela 4 , a produção de carne/ha depende da quantidade de bovinos mantidos na pastagem e do ganho em peso dos mesmos, que está diretamente relacionado com a qualidade da forragem nos diferentes períodos do ano. A diferença 
Tabela 4 - Ganho por área $(\mathrm{kg} / \mathrm{ha})$ de novilhos mestiços mantidos em sistema de pastejo.

\begin{tabular}{|c|c|c|c|c|c|c|c|c|c|}
\hline \multirow{2}{*}{ Tratamento } & \multicolumn{2}{|c|}{$27 / 11-2 / 1$} & \multicolumn{2}{|c|}{$02 / 1-07 / 2$} & \multicolumn{2}{|c|}{$07 / 2-15 / 3$} & \multicolumn{2}{|c|}{$15 / 3-20 / 4$} & \multirow{2}{*}{$\frac{\text { Total }}{\mathrm{kg} / \mathrm{ha}}$} \\
\hline & ua/ha & $\mathrm{kg} / \mathrm{ha}$ & ua/ha & $\mathrm{kg} / \mathrm{ha}$ & ua/ha & $\mathrm{kg} / \mathrm{ha}$ & ua/ha & $\mathrm{kg} / \mathrm{ha}$ & \\
\hline SS & 5,4 & 196 & 4,8 & 336 & 4,7 & 280 & 4,8 & 252 & 1064 \\
\hline SA & 7,1 & 348 & 6,3 & 596 & 6,2 & 497 & 6,3 & 447 & 1888 \\
\hline
\end{tabular}

$\mathrm{SS}$ - Bovinos sem suplementação; SA - Bovinos suplementados com $0,6 \%$ do peso.

na qualidade da forragem ao longo do ano, quando se trabalha com suplementação, deixa de ser tão prejudicial, visto que, o suplemento auxilia a corrigir as deficiências nutricionais da forragem, potencializando o ganho em peso.

Fernandes et al. (2002), avaliando o desempenho de bovinos Nelore, manejados em capim Marandu em condições de pastejo rotacionado observaram taxa de lotação de 5,0 ua/ha, produção de $770 \mathrm{~kg}$ de carne/ha e ganho de peso de $0,97 \mathrm{~kg} /$ bovino/dia durante o período das águas. Fernandes et al. (2003a,b) observaram produção de $948 \mathrm{~kg} / \mathrm{ha}$ durante o período das águas e $182 \mathrm{~kg} / \mathrm{ha}$ durante o período da seca, totalizando $1130 \mathrm{~kg} /$ ha/ano em pastagem de capim Marandu, manejada em sistema de lotação rotacionada. Nestes dois trabalhos, não foi utilizada a suplementação como estratégia de manejo.

\section{CONCLUSÕES}

A suplementação protéico-energética com $0,6 \%$ de MS em relação ao peso do animal, durante a época das águas, nas condições do presente trabalho, promoveu aumento no desempenho de bovinos mantidos em pastagem.

A suplementação de bovinos, durante o período das águas, promoveu aumento na produção de carne/ha.

Sistemas de pastejo manejados e adubados adequadamente permitem altas produções de massa seca, permitindo otimizar o desempenho animal.

\section{REFERÊNCIAS BIBLIOGRÁFICAS}

AGRICULTURALAND FOOD RESEARCH COUUNCIL. Energy and protein requeriments of ruminants. Royal: CAB, 1995. 59p.

BOIN, C. Formulação de rações para bovinos de corte em confinamento: custo mínimo. Piracicaba: FEALQ, 1994.

CORSI, M.; NÚSSIO, L.G. Manejo do capim elefante: correção e adubação do solo. In: SIMPÓSIO SOBRE
MANEJO DAS PASTAGENS, 10., 1993, Piracicaba. Anais... Piracicaba: ESALQ, 1993. p.87-115.

\section{EMPRESA BRASILEIRA DE PESQUISA}

AGROPECUÁRIA. Sistema brasileiro de classificação

de solos. Brasília: Embrapa Solos, 1999. 412p.

EMPRESA DE PESQUISA AGROPECUÁRIA DE MINAS GERAIS; INSTITUTO NACIONAL DE

METEREOLOGIA. Dados Climáticos de 2000, 2001 e 2002. Uberaba, 2003. Pastas 1-09 de 2000, 2001 e 2002.

EUCLIDES, V.P.B.; MACEDO, M.C.M.; OLIVEIRA, M.P. Animal production in tropical pastures recovered by subsoiling and fertilization in the cerrados of Brazil. In: INTERNATIONAL GRASSLAND CONGRESS, 19., 2001, Piracicaba. Proceedings... Piracicaba: FEALQ, 2001. p.841-842.

FERNANDES, L.O. et al. Avaliação do desempenho de bovinos da raça Nelore em diferentes gramíneas associadas ou não ao sorgo AG 2501 no processo de renovação de pastagem. In: CONGRESSO BRASILEIRO DAS RAÇAS ZEBUÍNAS, 5., 2002, Uberaba. Anais... Uberaba: ABCZ, 2002. p.345-347.

FERNANDES, L.O. et al. Desempenho de bovinos da raça Nelore em diferentes gramíneas forrageiras durante a época das águas. In: CONGRESSO INTERNACIONAL DE ZOOTECNIA, 5., 2003, Uberaba. Anais... Uberaba: ABZ/FAZU/ABCZ, 2003a. p.253-256.

FERNANDES, L.O. et al. Produção animal em diferentes gramíneas durante o período da seca associadas ou não ao sorgo $\mathrm{AG} 2501$, no processo de renovação de pastagens. In: CONGRESSO

INTERNACIONAL DE ZOOTECNIA, 5., 2003, Uberaba. Anais... Uberaba: ABZ/FAZU/ABCZ, 2003b. p.319-323.

HODGSON, J. Grazing management: science and practice. Champaign: Longman Group, 1990. 203p. 
KEARL, L.C. Nutrients requirements of ruminants in developing countries. Lugan: International Feestuffs Institute, 1982. 271p.

MARCONDES, P.C.F. et al. Desempenho de bovinos em pastagens de Brachiaria decumbens suplementados com proteína e energia no período das águas. In: REUNIÃO ANUAL DA SOCIEDADE BRASILEIRA DE ZOOTECNIA, 38., 2001, Piracicaba. Anais... Piracicaba: Sociedade Brasileira de Zootecnia, 2001. CD-ROM.

MOORE, J.E. et al. Effects of supplementation on voluntary forage intake, diet digestibility, and animal performance. Journal Animal Science, Baltimore, v.77, n.2, p.122-135, 1999. Supplement.

MOTT, G.O.; LUCAS, H.L. The design, conduct and interpretation of grazing trials on cultivated an improved pastures. In: INTERNATIONAL GRASSLAND CONGRESS, 6., 1952, Pensylvania. Proceedings... Pensylvania: State College, 1952. p.1380-1385.

NUNES, S.G. et al. Brachiaria brizantha cv. Marandu. Campo Grande: Embrapa-CNPGC, 1984. 31p. (EmbrapaCNPGC. Documentos, 21).

PEDREIRA, F.V.; MATTOS, H.B. Crescimento estacional de vinte e cinco espécies de variedades de capins. Boletim de Indústria Animal, Nova Odessa, v.38, n.2, p.117-143, 1981.

POPPI, D.P.; McLENNAN, S.R. Protein and energy utilization by ruminants at pasture. Journal Animal Science, Baltimore, v.73, n.2, p.278-290, 1995. Supplement.

PROHMANN, P.E.F. et al. Desempenho de novilhos mestiços submetidos à suplementação

Energética em pastagens na estação das águas. In: REUNIÃO ANUAL DA SOCIEDADE BRASILEIRA DE
ZOOTECNIA, 39., 2002, Recife. Anais... Recife: Sociedade Brasileira de Zootecnia, 2002. CD-ROM.

REIS, R.A. et al. Suplementação como estratégia para otimizar a utilização de pastagens. In: SIMPÓSIO GOIANO SOBRE MANEJO E NUTRIÇÃO DE BOVINOS DE CORTE E LEITE, 5., 2003, Goiânia. Anais... Goiânia: CBNA, 2003. p.85-120.

SILVA, D.J. Análise de alimentos: métodos químicos e biológicos. 2.ed. Viçosa, MG: UFV, 2002. 165p.

't MANNETJE, L. Measuring quantity of grassland vegetation. In: ___. Measuriment of grassland vegetation and animal production. Berkshire:

Commonwelath Agricultural Bureaux, 1978. p.63-95.

UNIVERSIDADE FEDERAL DE VIÇOSA. Manual de utilização do programa SAEG - Sistemas para Análises Estatísticas e Genéticas. Viçosa, MG, 1997. 59p.

WERNER, J.C. et al. Recomendação de adubação e calagem para forrageiras. In: RAIJ, B.V. (Ed.).

Boletim 100, recomendações de adubação e calagem para o estado de São Paulo. 2.ed. Campinas: Instituto Agronômico/Fundação IAC, 1997. p.261-276.

ZERVOUDAKIS, J.T. et al. Desempenho e características de carcaça de novilhos suplementados no período das águas. Revista Brasileira de Zootecnia, Viçosa, v.30, n.4, p.1381-1389, 2001.

ZIMMER, A.H.; EUCLIDES FILHO, K. As pastagens e a pecuária de corte brasileira. In:

SIMPÓSIO INTERNACIONAL SOBRE PRODUÇÃO ANIMAL EM PASTEJO, 1997,Viçosa, MG. Anais... Viçosa, MG: UFV, 1997. p.349-380. 
